I Universidade do Estado do Rio de Janeiro (Uerj), Departamento

de Antropologia, Rio de Janeiro, RJ, Brasil

maria.raquel.lima@uerj.br

https://orcid.org/ 0000-0003-0143-0558

Maria Raquel Passos Lima'

\title{
MARSHALL SAHLINS (1930-2021): PROVOCAÇÕES DE UMA ANTROPOLOGIA INQUIETA COMO LEGADO PARA O FUTURO
}

A notícia do falecimento de Marshall Sahlins, aos 90 anos de idade (27/I 2/193005/04/202 I), vem acompanhada de grande pesar e do inevitável reconhecimento de seu legado à antropologia, a ponto de não soar estranho alçá-lo ao status de clássico da disciplina. Antropólogo estadunidense, Sahlins deixou profundas influências na antropologia cultural da segunda metade do século XX até a contemporaneidade com obra marcada pelo senso de humor, às vezes ácido, e por um pensamento inquieto, provocador e sempre aberto a embates e mudanças.

Centrados principalmente na região do Pacífico, nas Ilhas Fiji e no Havaí, seus trabalhos contribuíram para o desenvolvimento da teoria antropológica, abordando questões que atravessam os campos da antropologia econômica, histórica e política, refletindo sobre parentesco, biologia, religião e sistemas de pensamento, a partir de um entendimento dinâmico e não reducionista da cultura.

À visão da cultura como algo em transformação, corresponde a abertura com que assimilou influências diversas ao longo de sua trajetória, permitindo que sua perspectiva sobre os fenômenos culturais, longe de se manter estática e objetificada, também se aprimorasse. Com formação de bacharel em artes (I95I) e mestre em antropologia (I952) pela Universidade de Michigan, em Ann Arbor, e doutorado pela Universidade de Columbia (I954), Sahlins iniciou sua carreira sob influência de Leslie White, cujo pensamento marcado por uma visão materialista e evolucionista se refletiu em suas primeiras publicações, como Evolution and culture (1960). 
No final da década de I960, Sahlins passou dois anos em Paris, sendo influenciado pelo ambiente intelectual francês e pelo estruturalismo de Claude Lévi-Strauss. Na década de I970, lançou diversos ensaios nos quais é um crítico insistente do homo economicus e da pretensão universalista da racionalidade econômica ocidental, apontando a base cultural e a relatividade do pensamento burguês como uma lógica cultural específica, que chamou de razão prática. "A sociedade afluente original" e "La pensée bourgeoise: a sociedade ocidental como cultura", publicados originalmente em Stone age economics (I972) e Culture and practical reason (i976) são alguns exemplos influentes.

O embate crítico contra a crença numa racionalidade prática universal atravessa sua obra chegando à interpretação da morte do capitão James Cook no Havaí em I779, com Islands of history (I985), e à disputa com o antropólogo cingalês Gananath Obeyesekere, que publicou The apotheosis of captain Cook (I992), acusando Sahlins de "exotização" dos povos havaianos. Sahlins rebate as críticas de Obeyesekere com a publicação de How "natives" think: about captain Cook, for example (1995), gerando assim um dos debates mais notáveis da história da antropologia. Nele, Sahlins reafirma a diversidade das ontologias e das lógicas culturais contra a ideia de uma racionalidade única, que imputa ao cingalês, cuja visão eurocêntrica corresponderia a uma "antiantropologia", por negar a especificidade cultural havaiana.

Com seus trabalhos no campo da antropologia histórica, Sahlins contribuiu para o desenvolvimento de questões teóricas, refletindo sobre a relação entre estrutura e evento, ao tratar do problema da mudança cultural. A partir da noção de "estrutura da conjuntura", apontou o equívoco em pensar "evento" e "estrutura" como oposição, fornecendo síntese que permite uma análise estrutural diacrônica da cultura.

Lecionou na Universidade de Michigan de I957 a I973, e a partir de 1974 ingressou no departamento de antropologia da Universidade de Chicago, cidade em que nasceu, tonando-se professor emérito de antropologia (the Charles F. Grey Distinguished Service Professor of Anthropology Emeritus). Professor visitante em universidades estrangeiras, recebeu honrarias de diversas associações e universidades. Publicou I 9 livros, produziu mais de ıoo artigos e ensaios, e seu trabalho foi traduzido para mais de 20 idiomas. Seus últimos livros publicados dedicaram-se à reflexão sobre parentesco e política, como What kinship is - and is not (2013), e On kings (2017), em coautoria com David Graeber.

Sahlins também se caracterizou por seu ativismo e pela defesa da liberdade de pensamento. Atuou ativamente contra a Guerra do Vietnã, tendo inventado uma forma de protesto realizada dentro da universidade conhecida como teach-in, com o objetivo de mobilizar as comunidades acadêmicas a debater e enfrentar desafios como as guerras dos EUA, as reformas neoliberais e os efeitos da globalização econômica. Em 2013, renunciou à Academia Nacional de Ciências (NAS) como forma de protesto contra a eleição de Napoleon Chag- 
non, cujos métodos de pesquisas e análises sociobiológicas desaprovava, e contra pesquisas militares com fins bélicos.

Manteve-se intelectualmente ativo e produtivo, sendo, desde 200I, editor executivo do selo Prickly Paradigm Press, especializado em pequenos panfletos como provocação ao pensamento contemporâneo, pelo qual publicou Waiting for Foucault, still (2002). O último projeto ao qual se dedicou foi a escrita de uma obra em três volumes sobre as culturas e o pensamento oceânicos, cujo primeiro volume, intitulado The new science of the enchanted universe, será publicado em 2022.

A antropologia perde um de seus grandes expoentes, mas, sobretudo, o mundo perde um pensador de mente perspicaz e espírito inconformista. Não cabe aqui, porém, qualquer pessimismo sentimental, pois seu legado intelectual permanece. Que suas ideias continuem em vivaz movimento, contribuindo para o desenvolvimento histórico da antropologia por caminhos tão desafiadores quanto profícuos.

Maria Raquel Passos Lima é professora adjunta do Departamento de Antropologia do Instituto de Ciências Sociais da Universidade do Estado do Rio de Janeiro (ICS/Uerj), doutora em antropologia cultural pelo Programa de Pós-Graduação em Sociologia e Antropologia (PPGSA/UFRJ) e bacharel em ciências sociais pelo Instituto de Filosofia e Ciências Sociais da Universidade Federal do Rio de Janeiro. 


\section{REFERÊNCIAS BIBLIOGRÁFICAS}

Graeber, David \& Sahlins, Marshall. (2017). On kings. Chicago: Hau Books, distributed University of Chicago Press.

Obeyesekere, Gananath. (I992). The apotheosis of captain Cook: European mythmaking in the Pacific. Princeton: Princeton University Press.

Sahlins, Marshall. (in press). The new science of the enchanted universe. Princeton: Princeton University Press.

Sahlins, Marshall. (2013). What kinship is - and is not. Chicago: The University of Chicago Press.

Sahlins, Marshall. (2002). Waiting for Foucault, still. Chicago: Prickly Paradigm Press.

Sahlins, Marshall. (1995). How "natives" think: about captain Cook, for example. Chicago: The University of Chicago Press. Sahlins, Marshall. (1985). Islands of history. Chicago: The University of Chicago Press.

Sahlins, Marshall. (1976). Culture and practical reason. Chicago: The University of Chicago Press.

Sahlins, Marshall. (I972). Stone age economics. Chicago: Aldine-Atherton.

Sahlins, Marshall \& Service, Elman (eds.). (1960). Evolution and culture. Ann Arbor: University of Michigan Press. 